\title{
Marine ecosystems of South America: from organisms to communities
}

\author{
Pablo Muniz ${ }^{*}$, Diana Szteren², Alicia Acuña ${ }^{1}$
}

\author{
${ }^{1}$ Oceanografía y Ecología Marina, Instituto de Ecología y Ciencias Ambientales (IECA) \\ ${ }^{2}$ Sección Zoología Vertebrados, Depto de Ecología y Evolución, Facultad de Ciencias. Iguá 4225, Montevideo 11400, Uruguay. \\ *Corresponding author: pmmaciel@fcien.edu.uy
}

Marine Sciences have a very high scientific production worldwide and there are always new research topics, which evidence the continuous progress of these disciplines. In Latin America, Marine Sciences development has had a significant advance in the last 20 years but has not yet achieved the ideal level, and fundamental aspects of some ecosystems and environments in the continent are still unknown. Nowadays, it is very important to promote new challenges in the topic as a way to develop research and management of oceans and their coasts. For this reason, the events conducted along 30 years by the Latin American Association of Researchers in Marine Sciences (ALICMAR-Asociación Latinoamericana de Investigadores en Ciencias del Mar) show a strong enthusiasm among the scientific community. The Latin American Congress of Marine Sciences (COLACMARCongreso Latinoamericano de Ciencias del Mar) is a biannual scientific meeting carried out in different cities of Latin America and the Caribbean uninterruptedly since 1983. These meetings have contributed to encourage research on marine science and related disciplines and to promote sustainable management of aquatic ecosystems.

The last edition, the XV COLACMAR "Connecting Marine Sciences in Latin America" was held from 27th to 31th October 2013 in Punta del Este (Uruguay). In this opportunity it was organized by the Faculty of Sciences (University of the Republic-UdelaR) and involved more than 1,000 researchers from 18 countries that presented over a thousand scientific research results. In these five intense days of work and broad discussion scientific results were presented through 16 thematic symposia, which included oral and poster presentations; conferences, seminars, and mini-courses. These activities allowed highlighted important results and recommendations in diverse marine topics developed in universities and management institutions from Latin America and the Caribbean, that was enriched by the relevant contribution of 23 speakers from international cutting-edge research worldwide, who are referents in their subjects.
As a result of these intensive days of presentations and discussions, the idea of embodying all these knowledge by publishing the results in a scientific journal arose. This idea is original in the scope of COLACMAR, since it never was done until now, and promoted the search and structuring of a dedicated volume in the Brazilian Journal of Oceanography (BJO). This journal is the continental referent in oceanography, achieved the objective of providing a major dissemination of research in marine science in South America and the Caribbean, among the international scientific community.

This special issue, entitled "Marine ecosystems of South America: from organisms to communities" brings together 17 articles covering a variety of topics in ecology, physiology, pollution, paleobiogeoclimate, hydrography and include studies from phytoplankton communities to top predators in marine ecosystems. These 17 articles are the result of the research of 73 authors from 46 institutions representing seven countries. The articles present a variety of techniques and methodologies ranging from genetics, fatty acid analysis and stable isotope analysis of pollutants, electrophoresis gels, using hydrographic and population variables for different purposes. These contributions represent innovative advances to marine ecosystems in the region, providing relevant global information.

The manuscripts published herein deal with a variety of topics, focuses and biotic groups. One group of four contributions deals with fish species from a physiological perspective to community ecology. In the article of Gadea Alvarez et al. it was addressed a characterization of gonadal maturation through the analysis of lipids and fatty acid content of ovaries of two flatfish species to understand their life history traits. A descriptive study on feeding ecology of single species was performed by analyzing its habitat and feeding habits in the coast of Buenos Aires, Argentina (Thompson et al.); and an assessment of periods and places of spawning aggregations of three reef species on the continental shelf of Bahia (Brazil) (Rocha França 
\& Olavo) by analyzing data on commercial catches and fishing effort. On a broader scale, an evaluation of environmental variables and a fish community to determine their spatial variations, allowed to highlight the importance of shallow environments as nursery areas on the Argentinian coast (Solari et al.).

A second group of articles are related from different perspectives with Crustaceans. The reproductive performance of a shrimp species was described by Zimmerman et al., who examined reproductive traits in the coast of San Paulo, Brazil, and recommend considering females weight gain when determining weight-dependent variables. A different aspect of reproduction is reported by Lezcano et al. who focused in cheliped form in the context of the reproductive strategy in two lobster species in Chile. Two contributions from the Crustacean ecology were presented by Fricke et al., who investigated the fecundity, growth and behavior of two amphipod species in laboratory experiments; and by Freitas dos Santos et al. who assessed population dynamics of a shrimp species in Macaé (Brazil), and the relationship between abundance and environmental variables. From a fisheries perspective, Santana et al. analyzed shrimp catches in two coastal lagoons of Uruguay during 25 years, and related them to ENSO events and to the growth of the species. Finally, Vanacor Barroso et al. in Espirito Santo (Brazil) undertook a laboratory procedure to compare 3 different diets in copepods performance and availability of fatty acids. They demonstrated which type of food was better for rearing this copepods species, and its ability to bioencapsulate nutrients, allowing their transfer in the food web.

Two contributions were carried out considering phytoplankton community and the environment. Martínez and Ortega delimitated the domains in the external Río de la Plata estuary showing that while salinity maintains an increasing trend toward the Oceanic domain, phytoplankton biomass decreases. In Guanabara Bay (Brazil), de Rezende et al. reported the coexistence of benthic and planktonic species, suggesting a considerable hydrodynamism in the study region and presented low diversity values indicating typical signals of environments subjected to eutrophication.
Another two contributions were developed in the Río de la Plata urban zone of Montevideo, the most urbanized region in Uruguay, where Muniz et al. reported significant changes, in the last 12 years, in the distributional patterns of heavy metals and organic pollutants in the sediments of the Montevideo Harbour. Also, Villar et al. reported a single cell electrophoresis method to detect damage in DNA of one the most abundant macrobenthic organisms in the Río de la Plata estuary, showing how pollutants affect negatively the genetic load of the snail and proposing that Heleobia australis could be used as a sentinel to evaluate the presence of mutagenic agents in this estuarine zone.

Pereira dos Santos et al. studied opal phytolith and isotopic structure of Brazilian restinga communities as proxies for paleobiogeoclimatic reconstructions. They concluded that this approach is a good proxy for the reconstruction of vegetation in the study area (Rio de Janeiro). Presta et al., from Argentina, studying tunicates from Ushuaia Bay showed that the mismatching in the population structure and pattern of densities of Fritillaria borealis between coastal and external zones would suggest the existence of two sub-populations susceptible to the influence of the anthropic impact in the study bay.

Finally, Szteren estimated the abundance of the two Pinniped species, at two poorly known sites in the Uruguayan coast. One of them was defined as a haul-out resting area for both species, especially in Winter, and the other one would be an incipient breeding area only for Southern sea lions.

The guest editors of this special issue of BJO would like to express their sincere acknowledgement to all the authors for their contributions to the present issue, to the reviewers for their assessments that to substantially improved the quality of accepted manuscripts, and a special thanks to the Editor in-chief of the Brazilian Journal of Oceanography, Dr. Ana Maria S. Pires Vanin, for the opportunity and constant encouraging by which this effort could develop into a product of very high academic quality. 